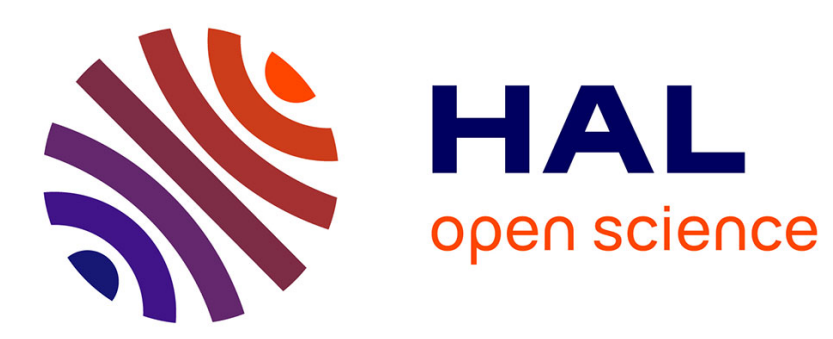

\title{
European study of the efficacy of a cross-linked gel stent for the treatment of glaucoma
}

\author{
Antonio M. Fea, Alain M. Bron, Mario A. Economou, Gianluca Laffi, Enrico \\ Martini, Michele Figus, Francesco Oddone
}

\section{- To cite this version:}

Antonio M. Fea, Alain M. Bron, Mario A. Economou, Gianluca Laffi, Enrico Martini, et al.. European study of the efficacy of a cross-linked gel stent for the treatment of glaucoma. Journal of Cataract and Refractive Surgery, 2020, 46 (3), pp.441-450. 10.1097/j.jcrs.0000000000000065 . hal-02619664

\section{HAL Id: hal-02619664 \\ https://hal.inrae.fr/hal-02619664}

Submitted on 25 May 2020

HAL is a multi-disciplinary open access archive for the deposit and dissemination of scientific research documents, whether they are published or not. The documents may come from teaching and research institutions in France or abroad, or from public or private research centers.
L'archive ouverte pluridisciplinaire HAL, est destinée au dépôt et à la diffusion de documents scientifiques de niveau recherche, publiés ou non, émanant des établissements d'enseignement et de recherche français ou étrangers, des laboratoires publics ou privés. 


\section{A real-life prospective study on the efficacy of the XEN 45 stent: a European study}

Running head: Real-life use of the XEN 45 stent

Authors: Antonio M. Fea, MD, Alain M. Bron, MD, Mario A. Economou, MD, PhD,

Gianluca Laffi, MD, Enrico Martini, MD, Michele Figus, MD, PhD, FEBO, Francesco

Oddone, $\mathrm{MD}, \mathrm{PhD}$

\section{Author affiliations:}

From the Eye Clinic (Fea), Department of Surgical Sciences, University Hospital, Corso Montevecchio 62, 10129 Turin, Italy, the Department of Ophthalmology (Bron), University Hospital, 21000 Dijon, France, the St Erik Eye Hospital (Economou), Karolinska Institute, 11230 Stockholm, Sweden, the Department of Ophthalmology (Laffi), S. Orsola Hospital, Bologna, Italy, the Department of Ophthalmology (Martini), Sassuolo Hospital, 41049 Sassuolo, Italy, the Department of Surgical, Medical, Molecular Pathology and of Critical Area (Figus), University of Pisa, 56100 Pisa, Italy, and the IRCCS GB Bietti Foundation (Oddone), Via di S. Stefano Rotondo 6, 00184 Rome.

Corresponding author: Antonio Fea, Eye Clinic, Department of Surgical Sciences, University of Turin, Corso Montevecchio 62, 10129 Torino, Italy. Email: antoniomfea@gmail.com. 
Disclosures: Dr. Fea is a consultant for Glaukos, Ivantis, iSTAR and EyeD Pharma, and has received travel support from Allergan and Sooft. Dr. Oddone is a consultant for Allergan, Santen, Sooft, Omikron Italia. Dr. Martini is on the speaker's board of Alcon, Allergan, and Santen.

Acknowledgments: The contribution of IRCCS Fondazione Bietti to this paper was supported by the Italian Ministry of Health and by Fondazione Roma.

\section{ABSTRACT}

Purpose: This study investigated the efficacy and safety of a cross-linked collagen stent (XEN 45) with or without cataract surgery in the treatment of glaucoma.

Setting: Real-life setting.

Design: Prospective, open-label, multicenter clinical trial.

Methods: Eligible patients with glaucoma inadequately controlled by treatment, or poor compliance or intolerance to topical therapy were included. Patients were divided into those with implant only (solo group; phakic and pseudophakic patients) and implant combined with cataract surgery (combo group). Differences in average intraocular pressure (IOP) and number of medications between baseline and study end (12 months), and the rate of qualified and complete success were evaluated.

Results: Overall, there were 115 patients in the solo group (43 phakic and 72 pseudophakic) and 56 in the combo group. Compared with baseline, mean IOP $(23.9 \pm 7.6$ to $15.5 \pm 3.9)$ and number of medications $(3.0 \pm 1.1$ to $0.5 \pm 1.0)$ decreased significantly at study end $(P<0.001$ for both). A $>20 \%$ and $>30 \%$ reduction in IOP from baseline was achieved by $72.3 \%$ and $52.6 \%$ of patients, respectively. IOP at one week post-op was a predictor of success, and the 
needling rate was inversely correlated to early post-op IOP. The number of pre-operative medications and patientage were not significantly associated with failure.

Conclusions: Insertion of the XEN 45 stent alone or combined with phacoemulsification is effective and safe in the treatment of open angle glaucoma, with a substantial reduction in IOP and number of medications. Future randomized, comparative studies on the use of this device are warranted. 


\section{INTRODUCTION}

Glaucoma is a group of diseases leading to a chronic and progressive optic neuropathy and loss of vision. It affects more than 60 million patients and represents the second cause of blindness worldwide; ${ }^{1,2}$ its prevalence is increasing due to aging of the world's population. ${ }^{3,4}$ Primary open-angle glaucoma (POAG) is the most common form of the disease. ${ }^{4}$ The aim of all glaucoma treatments is to decrease intraocular pressure (IOP), since IOP is the only modifiable parameter among other well-identified risk factors. The modalities of treatment should be individualized considering the characteristics of the disease (type of glaucoma, stage, rate of progression) and the patient (age, lifestyle, expectations). Increasing attention to quality of life has emerged in recent years and new surgical techniques have been designed to reduce possible morbidity connected with traditional glaucoma surgery.

Target IOP is most often used in clinical practice and is defined as a decrease of at least $20 \%$ in early glaucoma and $30 \%$ in moderate glaucoma versus baseline IOP.XEN 45 is a new device consisting of a porcine gelatin stent cross-linked with glutaraldehyde and comes preloaded in an injector; it has been designed to create a channel from the anterior chamber (AC) to the subconjunctival space and to allow aqueous humor outflow when inserted through a small corneal incision via a minimally invasive procedure. ${ }^{5-7}$ Several studies have demonstrated that the device is both effective and safe, either alone $e^{7-10}$ or combined with other interventions. ${ }^{11-17}$ XEN 45 has been approved by the FDA on the basis of the favorable results in terms of efficacy and safety in a pivotal study on 65 patients with glaucoma refractory to other therapeutic interventions. ${ }^{9}$ The aim of our study was to evaluate the efficacy and safety of XEN 45 in a real-life setting, either alone or combined with standard phacoemulsification, in a group of patients with glaucoma. 


\section{PATIENTS AND METHODS}

\section{$\underline{\text { Study design and participants }}$}

This was a prospective, open-label, multicenter clinical trial on real-life patients from 7 European centers, with data collected according to a common protocol. In all centers, the study protocol was approved by the local Ethics Committee, and patients gave written informed consent prior to enrollment. The study was conducted in accordance with the ICH Harmonized Tripartite Guidelines for Good Clinical Practice and principles of the Declaration of Helsinki.

Eligible patients had glaucoma inadequately controlled by treatment, or a poor compliance or intolerance to topical therapy. Patients with narrow-angle glaucoma, ocular pemphigoid, phacodonesis, or patients with a conjunctival scar, which in the opinion of the surgeon could compromise the outcome of the procedure, were excluded. Contrary to recommendations in the instruction manual of the XEN 45, and considering the real-life setting of the present study, patients who had previously undergone surgery for glaucoma or who had pseudoexfoliation were not excluded.

Patients with a significant cataract (decrease of visual acuity $\geq 7 / 10$ or with significant cataract-related visual symptoms) were treated with standard phacoemulsification combined with implantation of the XEN 45 device. Patients were divided into two groups: implant only (solo group) and implant combined with cataract surgery (combo group); within the solo group, phakic and pseudophakic patients were also analyzed separately.

\section{$\underline{\text { XEN } 45 \text { stent and surgical technique }}$}

The XEN 45 gel stent (Allergan, Dublin, Ireland) is made of porcine collagen cross-linked with glutaraldehyde. The cross-linked collagen stent is $6 \mathrm{~mm}$ long, has a $45 \mu \mathrm{m}$ inner lumen diameter, and is preloaded into a single-use injector. Standard ophthalmic surgical techniques 
were used to prepare patients and eyes. In the combo group, all subjects underwent standard corneal phacoemulsification with intraocular lens implantation. If the surgeon considered it necessary, acetylcholine was injected into the $\mathrm{AC}$ to constrict the pupil before implant of a cross-linked collagen stent. The majority of needlings were performed with 5-fluorouracil (5$\mathrm{FU}$ ) at the discretion of the surgeon. Intraoperative $0.1 \mathrm{~mL}$ mitomycin $\mathrm{C} 0.02 \%$ (MMC) was injected sub-conjunctivally using a $30 \mathrm{G}$ hypodermic needle under Tenon capsule and spread with a microsponge applied to the conjunctiva in the superior nasal quadrant where the implant was to be inserted before the implant was injected or, in case of cataract extraction, before phacoemulsification (performed in 13 patients at the surgeon's discretion). Using an ab interno approach, the preloaded injector needle was inserted through a $1.8 \mathrm{~mm}$ corneal incision in case of the solo procedure (or a $2.2 \mathrm{~mm}$ corneal incision in case of combo with cataract) opposite to the site of desired implantation after the AC was filled with the highly cohesive viscoelastic device. The needle was then directed across the AC towards the superonasal quadrant. Intraoperatively, a goniolens could be used at the surgeon's discretion to verify placement through the angle to avoid trauma to the iris, iris root, or the trabecular meshwork. The implant tracked $3.0 \mathrm{~mm}$ posterior to the limbus exiting through the sclera into the subconjunctival space. Approximately 1 to $2 \mathrm{~mm}$ of the implant was left in the AC to provide a connection from the AC to the subconjunctival space. Viscoelastic material was removed from the AC by irrigation/aspiration in the combo group or by washing with saline in the solo group.

\section{$\underline{\text { Post-operative management }}$}

Topical IOP-lowering medications, as well as systemic IOP-lowering medications, were suspended on the day of surgery. Antibiotic-corticosteroid therapy or corticosteroid monotherapy was administered and progressively withdrawn over one month. In the 
following months, a drop of corticosteroid was administered at the dosage and schedule according to the physicians' preferences.

After surgery, needling was performed if necessary either at slit-lamp or in the operating room according to the surgeon's preference (IOP increase over target, flat bleb or fibrotic bleb, or high risk of bleb failure in the investigator's opinion). In case of repeated failure after needling, IOP-lowering medications were restarted. The number of post-operative needling procedures allowed were left to the investigator's discretion. If the IOP remained higher than the patient's target pressure in two consecutive measurements after needling and/or if, according to the surgeon's opinion, bleb revision was not possible, IOP-lowering medications were restarted with the regimen decided by the physician. IOP-lowering medications were also started while waiting for the needling procedure, if necessary.

\section{$\underline{\text { Assessments }}$}

Patients were evaluated with a baseline pre-operative visit (within 1 month prior to surgery) and follow-up assessments were planned at 1 day, 1 week, and 1, 3, 6, 9, and 12 months after surgery. During the baseline visit, patients' personal and anamnestic data were collected as follows: IOP measurement assessed by two operators, best-corrected visual acuity evaluation, an examination of the anterior segment and the fundus, and a computerized visual field testing. The two-operator IOP measurement was repeated at each post-operative visit at $9 \mathrm{am}$ ( \pm 1 hour); if in the opinion of the surgeon the bleb was cystic or flat, or in the case of IOP increase over target in two consecutive measurements at least one day apart, needling with 5FU or MMC was performed according to the center protocol. 


\section{$\underline{\text { Endpoints }}$}

The primary endpoints were the reduction in mean IOP and number of medications between baseline and study end. The rates of qualified success (defined as IOP $\leq 18,16$, and 14 $\mathrm{mmHg}$, and a $>20 \%$ and $>30 \%$ IOP reduction from baseline, irrespective of pharmacological treatment) at 12 months and complete success (same IOP reductions as above and without pharmacological treatment) were also evaluated and compared between groups. Failures were considered IOP $<4 \mathrm{mmHg}$ for more than two post-operative visits, need for further glaucoma surgery or surgery for complications. We also calculated whether IOP on day $1(<6,8$ or 10 $\mathrm{mmHg}$ ) was related to complete success. Moreover, we evaluated whether an increase in IOP of $>4 \mathrm{mmHg}$ or $>6 \mathrm{mmHg}$ between the first three post-operative visits (at 1 day, 1 week, and 1 month) was related to the success rate or to the number of needling procedures. The preoperative number of eye drops and patient age were evaluated as possible risk factors for failure or to the number of needling procedures.

\section{Statistical analysis}

All analyses were performed on the intent-to-treat (ITT) population. Patients with more than $30 \%$ missing data were dropped and case-wise deletion was used in the remaining data set.

Variables with a normal distribution were expressed as mean \pm standard deviation and compared using a paired or unpaired t-test. Categorical variables were expressed as numbers (percentages) and compared with Fisher's exact test or Mann-Whitney test as appropriate. Correlations were evaluated using the Pearson coefficient for Gaussian and Spearman for non-Gaussian distributed variables. A $P$ value of $<0.05$ was considered significant and all tests were two-tailed. Analyse-it 4.8 and Prism 8 software were used for the analysis. 


\section{RESULTS}

Demographic and baseline characteristics

In total, 298 patients were enrolled; 171 patients had $\geq 9$ months of follow-up and were included in the analysis. As no significant differences were detected at baseline between the enrolled population and the patient population with $\geq 9$ months follow-up (Table 1), the analyzed sample can be considered representative of the entire population. Of the 171 patients, 115 were treated with the XEN-45 gel stent only (solo group; 43 phakic and 72 pseudophakic) and 56 with the XEN-45 gel stent plus phacoemulsification (combo group); two patients with mixed mechanism glaucoma were included, one in each treatment group (Table 2).

Twelve patients ( 8 in the solo group and 4 in the combo group) underwent other surgical procedures; data from these patients were considered until the last visit before surgery. Rupture of the stent occurred during the needling procedure in one patient; this data was, however, included in the analysis.

Of the 171 patients with baseline assessment, data were available for 131, 166, 166, 148, 145, 141, and 137 patients at 1 day, 1 week, and 1, 3, 6, 9, and 12 months after surgery, respectively. At the 12-month visit, data were available for $87.1 \%$ of patients (149/171), including patients who needed other glaucoma surgery.

Despite not being a randomized study, baseline characteristics of the combo and solo groups were mostly similar, with the exception of IOP and number of medications, which were significantly higher in the solo group than in the combo group; the solo group also had significantly higher visual acuity, which was as expected (Table 2). 


\section{Efficacy}

Compared with baseline, mean IOP and number of medications decreased significantly at 12month follow-up (from $23.9 \pm 7$ to $15.5 \pm 3.9$ and from $3.0 \pm 1.1$ to $0.5 \pm 1.0$, respectively; both $P<0.001$ ) (Figure 1). Figure 2 shows the same set of IOP data presented in a scatterplot format to show the changes in pressure. Although 28 patients were receiving acetazolamide combined with topical therapy at baseline (Table 2), no patients received acetazolamide during the post-operative period.

One week and 1 month post-operative IOP were correlated with final IOP $(P=0.04$ and $P=$ 0.01 respectively), whereas there was no correlation between 1 day post-operative IOP and final IOP (Table 3). Patients with a 1 week post-operative IOP $<6,8$ or $10 \mathrm{mmHg}$ had a significantly higher probability of success defined as an IOP $\leq 14,16$ or $18 \mathrm{mmHg}$ at the final follow-up visit, as did patients with a 1 month post-operative IOP $<10 \mathrm{mmHg}$ (Table 3). In addition, patients with a change in IOP between 1 week and 1 month of $<4$ or $6 \mathrm{mmHg}$ had a significantly higher chance of achieving an IOP $\leq 16$ or $18 \mathrm{mmHg}$ at the final follow-up visit (Table 3).

Neither patient age nor the number of medications at baseline were related with treatment outcome.

The number of needling procedures was significantly correlated with 1 day $(\mathrm{r}=0.24, P=$ 0.006), 1 week $(\mathrm{r}=0.27, P<0.001)$, and 1 month $(\mathrm{r}=0.32, P<0.0001)$ post-operative IOP, but not with the pre-operative number of medications or pre-operative IOP, nor to patient age. Patients subjected to needling had a similar pre-operative IOP (no needling, 23.3 \pm 7.5 ; needling, 24.4 $\pm 7.7 ; P=0.96$ ), although post-operative IOP was significantly less in the group that did not undergo needling (no needling, 14.8 \pm 3.1 ; needling, 16.5 $\pm 4.5 ; \mathrm{P}=0.01$ ) with no differences in the number of medications pre- and post-operative (no needling: pre-, 2.9 \pm 1.2 ; post-, $0.3 \pm 0.9$; needling: pre-, $3 \pm 0.9$ and $0.8 \pm 1.2$ ). All three patients with uveitic glaucoma 
were subjected to needling (one patient once and two patients twice each).Patients who did not undergo needling had a significantly higher rate of complete success at the end of followup period compared with patients treated with needling, with an IOP $\leq 14 \mathrm{mmHg}$ in $68.8 \%$ vs. $46.7 \%,(P=0.02), \leq 16 \mathrm{mmHg}$ in $66.7 \%$ vs. $41.9 \%,(P=0.002)$, and $\leq 18 \mathrm{mmHg}$ in $66.7 \%$ vs. $39.3 \%$ of patients $(P=0.001)$.

Compared with baseline, IOP decreased in both the combo and solo groups at the final visit (from $21.42 \mathrm{mmHg}$ to $15.81 \mathrm{mmHg}$, and from $25.03 \mathrm{mmHg}$ to $15.36 \mathrm{mmHg}$, respectively) (Figure 3). At 1 week, IOP was significantly lower in the solo group compared with the combo group $(P=0.04)$, but no significant differences were detected at the following visits. Throughout the follow-up period, the mean number of medications was not significantly different between the two groups.

No significant differences in IOP or the number of medications were detected between phakic and pseudophakic patients in the solo group at the end of the follow-up period (Figure 4).

The mean difference between baseline and the end of the follow-up period in IOP and the number of medications was significantly higher in the solo group compared with the combo group ( $P=0.0032$ and $P<0.0001$, respectively) (Table 4). Compared with baseline, IOP and the number of medications were reduced at the final visit by $38.6 \%$ and $83.7 \%$ in the solo group and by $26.2 \%$ and $80.1 \%$ in the combo group, respectively. Phakic patients achieved the highest percentage reduction for both parameters.

Table 5 shows the final results at the 12-month follow-up visit. Overall, a $>20 \%$ and $>30 \%$ IOP reduction from baseline was achieved by $72.3 \%$ and $52.6 \%$ of patients, respectively, and $71.5 \%$ of patients were without medications $(70.8 \%$ and $71.9 \%$ in the combo and solo groups, respectively). There were no significant differences between phakic and pseudophakic patients in terms of the percentage of patients with a $>20 \%$ and $>30 \%$ IOP 
reduction from baseline. Similarly, no significant differences were found for either qualified or complete success, with IOP $\leq 18$ and $\leq 16 \mathrm{mmHg}$ with or without medications, respectively, although more patients in the solo group achieved complete success with IOP $\leq 14 \mathrm{mmHg}$ and no medications compared with the combo group ( $41.6 \%$ vs. $22.9 \%$, respectively; $P=0.03$ ) (Table 5). For qualified success in the solo group, a higher percentage of phakic patients obtained IOP $\leq 16$ and $\leq 14 \mathrm{mmHg}$ compared with the pseudophakic group $(72.4 \%$ and $62.1 \%$ vs. $70.0 \%$ and $40.0 \%$, respectively), but these differences were not statistically significant (Table 5).

In the subpopulation of patients who had undergone previous surgery for glaucoma or other ocular procedures no differences were observed in the number of needlings, although it is worthwhile mentioning that conjunctival perforation occurred in one case and hypoathalamia was seen in another case that resolved with medical therapy. In addition, one patient who had undergone previous iridectomy was subjected to successive trabeculectomy and one with prior trabeculectomy needed an Ahmed valve. The number of re-interventions in the group with prior ocular interventions was numerically higher compared to those without, although statistical analysis was not possible due to the small number of patients. In consideration of the different diagnoses, the only subgroup with a sufficient number of patients was those with pseudoexfoliation. There were no significant differences between these patients and the remaining group in terms of number of drugs administered $(0.2 \pm 0.5$ vs $0.6 \pm 1.0)$ or needlings $(1.0 \pm 1.3$ vs $0.8 \pm 1.2)$ at last follow-up. In addition, IOP at last follow-up was also similar

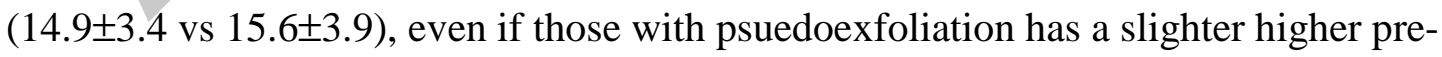
operative IPO (25.0 \pm 6.5 vs $23.6 \pm 7.7)$. Of the three patients with uveitis, one had been previously subjected to trabulectomy and needed a Baerveldt valve. The other two patients had an IOP at follow-up that was slightly higher than the entire group (21.1 vs 19.3, 
respectively) and a mean of 2 vs 3 drugs administered. Bleeding in the anterior chamber was also observed in one of these patients.

\section{$\underline{\text { Safety }}$}

Post-operative complications are reported in Table6. Additional surgery was performed in 12 (7\%) patients (8 in the solo group and 4 in the combo group) including: trabeculectomy $(n=8)$, Ahmed valve implant $(n=1)$, Baerveldt valve implant $(n=1)$, vitrectomy for malignant glaucoma $(n=1)$, and bleb revision for exposure to the cross-linked collagen stent $(n=1)$. Four of the additional procedures were done on patients who had undergone previous glaucoma surgery.

Overall, 147 needlings were performed in 79 patients (46.2\%), corresponding to $1(n=41), 2$ $(n=21), 3(n=10), 4(n=3), 5(n=2)$, and 6 procedures $(n=2)$. The needling rate was significantly higher in patients in the combo group compared with the solo group $(48.21 \%$ vs. $45.22 \%, P<0.01)$, and in pseudophakic vs. phakic patients $(45.83 \%$ vs. $44.19 \%, P=0.002)$ (Table 7).

Cases of hyphema, hypoathalamia, choroidal detachment, and fibrin reaction were all treated with medical therapy and had a post-operative course that was broadly similar to entire population. The case of perforation was treated with suture of the conjunctiva and topical antibiotic therapy, and resolved after 4 weeks. The case of stent rupture did not require intervention. The cases of stent repositioning and stent in the anterior chamber underwent removal and reimplantation of the stent. All these cases had outcomes that were similar to the entire group. The case of malignant glaucoma manifested on the fourth day; following 48 hours of medical therapy with atropine and acetazolamide the patient was subjected to vitrectomy $23 \mathrm{G}$ (VPP) associated with irido-zonular-hyaloidectomy of the anterior chamber. The outcome was satisfying with good control of ocular pressure $(19.0 \mathrm{mmHg}$ at 6 months; 
timolol $0.1 \%$ every morning), but visual acuity was reduced to $1 / 10$. The reduced visual was partially attributable to pre-existing age-related dry maculopathy. There were no cases of endophthalmitis.

\section{DISCUSSION}

This prospective, open-label, multicenter clinical trial aimed to demonstrate the effectiveness and safety of the XEN 45 stent in patients with uncontrolled glaucoma or with poor compliance or intolerance to medical therapy in a real-life setting. In our study, the $35.2 \%$ reduction seen in IOP is consistent with previous prospective studies, which showed reductions of $35.6 \%,{ }^{7} 31 \%,{ }^{16}$ and $30.4 \%{ }^{18}$. Although our inclusion criteria differed, the final (one year) IOP of $15.5 \mathrm{mmHg}$ is in line with that reported by other studies: $15.9 \mathrm{mmHg}{ }^{7}$ $13.9 \mathrm{mmHg},{ }^{16}$ and $14.9 \mathrm{mmHg}^{18}$, suggesting that the results obtained with the use of XEN 45 stent are consistent, at least in a Caucasian population. It is of note that both mean IOP and the percentage of patients with IOP $\leq 18$ and $16 \mathrm{mmHg}(83.7 \%$ and $60.7 \%$ of patients with IOP $\leq 18 \mathrm{mmHg}$ and $\leq 15 \mathrm{mmHg}$, respectively, in the Apex study ${ }^{18}$ compared with $81 \%$ and $70 \%$ of patients with IOP $\leq 18 \mathrm{mmHg}$ and $\leq 16 \mathrm{mmHg}$, respectively, in our study) are very similar to those reported in the multicenter Apex group study. This is despite the fact that, in the Apex study, only POAG patients with moderate severity and without previous glaucoma surgery were included.

Previous studies have speculated that a low IOP in the early post-trabeculectomy period may be predictive of a more favorable outcome. Some have suggested that lower IOPs on first post-operative day are predictive of longer-term success, ${ }^{19}$ while others found that IOPs at the first month ${ }^{20}$ were a predictive factor for success ${ }^{21}$ Karimi et al. found that low IOP on day 1 after XEN gel implantation may be a positive predictive factor for final outcomes (Table 8$){ }^{22}$ In our study, 1 week and 1 month post-operative IOP were correlated with the final IOP, 
whereas day 1 post-operative IOP was not. By grouping patients according to IOP at day 1, 1 week and 1 month, those with a lower IOP at 1 week had a higher chance of success. Patients with an IOP difference of $<4$ or $<6 \mathrm{mmHg}$ between the 1 week and 1 month postoperative visits had a higher probability of having a final IOP $\leq 16$ or $18 \mathrm{mmHg}$. Early IOP post-surgical procedures for glaucoma may be influenced by a variety of different factors and this might explain why we did not observe any relationship with the success rate and day 1 post-operative IOP. Week 1 post-operative IOP seems to hold a greater predictive value towards the final IOP. Similar results were obtained when comparing the IOP difference between week 1 and month 1 .

Previous authors used anterior segment-optical coherence tomography to find predictors of surgical success. ${ }^{23,24}$ Although the bleb resulting after implantation of a cross-linked collagen stent is smaller and easier to study compared to the one after trabeculectomy, bleb analysis is time consuming and there are no widely accepted definitions of bleb morphology. The possibility of summarizing a variety of factors in a single variable (early post-operative IOP) that can be a reasonable predictor of the longer IOP target is promising, although it should be confirmed by further studies. Midha and colleagues demonstrated that eyes with lower IOP on day 1 were less likely to require needling. ${ }^{25}$ Similarly, we found a significant correlation with IOP at day 1 , week 1 and month 1 , but not with pre-operative IOP patient age, number of pre-operative medications, or number of needling procedures. Taken together, these observations strongly support the hypothesis that early post-operative IOP can predict the final surgical outcome and suggest that closer follow-up is warranted in patients with a relatively higher post-operative IOP.

The percentage IOP reduction in this sample is not a meaningful way of measuring success due to the fact that starting IOP pressures were significantly different between the solo and combo groups, and a floor effect may not be excluded. As far as final pressures are 
concerned, which are an important marker of success, there was no significant difference between the solo and combo groups.

The solo group demonstrated a significantly higher percentage of patients with IOP $\leq 14 \mathrm{mmHg}$ at the 12-month follow-up visit, a significantly higher mean decrease of medications, and significantly fewer patients who underwent needling. Taken together, these data suggest that the combination of phacoemulsification with the XEN 45 gel stent may be slightly less effective compared with implantation of the same stent alone. If we do not concentrate only on mean pressure, but analyze our data in more detail, it is apparent that there are differences between the two groups and that these differences are clinically meaningful. This can also explain some of the different results described in the literature. Our results are in line with the those reported by Mansouri and colleagues. ${ }^{16}$ Widder et al. ${ }^{10}$ similarly reported a better success rate in solo surgery, while other authors could not show any difference between solo and combo surgery. ${ }^{13,15,18}$ It should be noted, nevertheless, that both Karimi et al. ${ }^{15}$ and the Apex study ${ }^{18}$ only compared mean IOPs between the two groups, which was also not significantly different in our sample.

The needling rate in our sample was higher (46.1\%) compared with previous studies (range $2.4 \%-43 \%^{26}$ ) and probably reflects a proactive approach to needling. It should also be noted that no strict guidance was prospectively defined and that different centers used different approaches. In the literature, nevertheless, there is no clear and objective criteria for needling other than increased IOP or appearance of bleb, which is a somewhat subjective criterion. Furthermore, in our group, some surgeons prefer to establish a limit for the number of needling procedures (i.e., no more than 2 or 3), because they fear the cumulative effect of antimetabolite injections or feel that if two needling procedures are ineffective the probability of success with a third needling would be very low; others, however, may proceed with needling whenever they deemed it necessary and eventually decided to use steroids instead of 
antimetabolites to limit potential adverse events. Further research is definitely warranted in this area to better define the number, type, and indications for needling. Additional surgery was required by $7 \%$ of our patients and one-third of those requiring additional surgery had glaucoma surgery prior to implantation of the XEN 45 stent. Little is known about the results of implantation of a cross-linked collagen stent on patients with previous surgery, although Karimi et al. ${ }^{15}$ suggested that the XEN implant was equally effective in patients with or without previous glaucoma surgery (18 patients of 226). Most complications reported in our study were self-limited with medical therapy (hyphema, choroidal detachment, fibrinoid reaction in the AC), but a case of malignant glaucoma, which required vitrectomy, also occurred as well erosion through the conjunctiva. Although rare, these complications may lead to a severe impairment of visual function. ${ }^{27}$

The strengths of this study are represented by its prospective, multicenter (with a common protocol), and comparative design, its real-life setting, the relatively large number of cases, and the subanalysis between phakic and pseudophakic patients. This study is limited by its non-randomized design, and by the differences, albeit slight, at baseline between the combo and solo groups in terms of IOP and number of medications. Finally, baseline unmedicated IOP was not recorded, due to the lack of a wash out period.

In conclusion, our study showed that insertion of the XEN 45 stent alone or combined with phacoemulsification is effective and safe in the treatment of open angle glaucoma, with a substantial reduction of IOP and number of medications, a good success rate, and a low number of adverse effects. Future randomized, comparative studies with a long-term followup on the use of this device are warranted. 


\section{WHAT WAS KNOWN}

- In patients with glaucoma, the association with cataract is common and combined surgical therapy is often needed.

- The XEN 45 stent was effective and safe in the surgical treatment of glaucoma.

\section{WHAT THIS PAPER ADDS}

- The use of the XEN 45 stent, either alone or in combination with phacoemulsification, is effective and safe in the treatment of open angle glaucoma in a "real-life setting".

- The combination of the XEN 45 stent plus phacoemulsification may be slightly less effective than implantation of the same stent alone.

- Early post-operative IOP may predict the final surgical outcome suggesting closer follow-up in patients with a relatively higher post-operative IOP is warranted.

\section{SYNOPSIS}

In a "real-life" setting, the XEN 45 stent was effective and safe in treatment of open angle glaucoma, either alone or in combination with phacoemulsification.

\section{ACKNOWLEDGEMENTS}

Writing and editorial assistance was provided to the authors by Maria Carla Brunenghi and Melanie Gatt $(\mathrm{PhD})$, an independent medical writer, on behalf of Health Publishing \& Services Srl and funded by Allergan plc, Dublin, Ireland, at the request of the investigator. All authors met the ICMJE authorship criteria. Neither honoraria nor payments were made for authorship. 


\section{REFERENCES}

1. Kingman S. Glaucoma is second leading cause of blindness globally. Bull World Health Organ 2004; 82:887-888

2. Quigley HA, Broman AT. The number of people with glaucoma worldwide in 2010 and 2020. Br J Ophthalmol 2006; 90:262-267

3. Lavia C, Dallorto L, Maule M, Ceccarelli M, Fea AM. Minimally-invasive glaucoma surgeries (MIGS) for open angle glaucoma: A systematic review and meta-analysis. PLoS One 2017; 12:e0183142

4. Tham YC, Li X, Wong TY, Quigley HA, Aung T, Cheng CY. Global prevalence of glaucoma and projections of glaucoma burden through 2040: a systematic review and meta-analysis. Ophthalmology 2014; 121:2081-2090

5. De Gregorio A, Pedrotti E, Stevan G, Bertoncello A, Morselli S. XEN glaucoma treatment system in the management of refractory glaucomas: a short review on trial data and potential role in clinical practice. Clin Ophthalmol 2018; 12:773-782

6. Dupont G, Collignon N. Nouvelle approche chirurgicale dans le glaucome à angle ouvert: le XEN Gel Stent, une technique micro-invasive. Rev Med Liege 2016; 71:9093

7. Grover DS, Flynn WJ, Bashford KP, Lewis RA, Duh YJ, Nangia RS, Niksch B. Performance and Safety of a New Ab Interno Gelatin Stent in Refractory Glaucoma at 12 Months. Am J Ophthalmol 2017; 183:25-36

8. Heidinger A, Schwab C, Lindner E, Riedl R, Mossbock G. A Retrospective Study of 199 Xen45 Stent Implantations From 2014 to 2016. J Glaucoma 2019; 28:75-79

9. Schlenker MB, Gulamhusein H, Conrad-Hengerer I, Somers A, Lenzhofer M, Stalmans I, Reitsamer H, Hengerer FH, Ahmed IIK. Efficacy, Safety, and Risk 
Factors for Failure of Standalone Ab Interno Gelatin Microstent Implantation versus Standalone Trabeculectomy. Ophthalmology 2017; 124:1579-1588

10. Widder RA, Dietlein TS, Dinslage S, Kuhnrich P, Rennings C, Rossler G. The XEN45 Gel Stent as a minimally invasive procedure in glaucoma surgery: success rates, risk profile, and rates of re-surgery after 261 surgeries. Graefes Arch Clin Exp Ophthalmol 2018; 256:765-771

11. De Gregorio A, Pedrotti E, Russo L, Morselli S. Minimally invasive combined glaucoma and cataract surgery: clinical results of the smallest ab interno gel stent. Int Ophthalmol 2018; 38:1129-1134

12. Galal A, Bilgic A, Eltanamly R, Osman A. XEN Glaucoma Implant with Mitomycin C 1-Year Follow-Up: Result and Complications. J Ophthalmol 2017; 2017:5457246

13. Hohberger B, Welge-Lussen UC, Lammer R, MIGS: therapeutic success of combined Xen Gel Stent implantation with cataract surgery. Graefes Arch Clin Exp Ophthalmol $2018 ; 256: 621-625$

14. Jimenez-Roman J, Lazcano-Gomez G, Martinez-Baez K, Turati M, Gulias-Canizo R, Hernandez-Zimbron LF, Ochoa-De la Paz L, Zamora R, Gonzalez-Salinas R. Effect of phacoemulsification on intraocular pressure in patients with primary open angle glaucoma and pseudoexfoliation glaucoma. Int J Ophthalmol 2017; 10:1374-1378

15. Karimi A, Lindfield D, Turnbull A, Dimitriou C, Bhatia B, Radwan M, Gouws P, Hanifudin A, Amerasinghe N, Jacob A. A multi-centre interventional case series of 259 ab-interno Xen gel implants for glaucoma, with and without combined cataract surgery. Eye (Lond) 2019; 33:469-477

16. Mansouri K, Guidotti J, Rao HL, Ouabas A, D'Alessandro E, Roy S, Mermoud A. Prospective Evaluation of Standalone XEN Gel Implant and Combined 
Phacoemulsification-XEN Gel Implant Surgery: 1-Year Results. J Glaucoma 2018; 27:140-147

17. Perez-Torregrosa VT, Olate-Perez A, Cerda-Ibanez M, Gargallo-Benedicto A, Osorio-Alayo V, Barreiro-Rego A, Duch-Samper A. Combined phacoemulsification and XEN45 surgery from a temporal approach and 2 incisions. Arch Soc Esp Oftalmol 2016; 91:415-421

18. Reitsamer H, Sng C, Vera V, Lenzhofer M, Barton K, Stalmans I, Apex Study G. Two-year results of a multicenter study of the ab interno gelatin implant in medically uncontrolled primary open-angle glaucoma. Graefes Arch Clin Exp Ophthalmol 2019; 257:983-996

19. Downes SM, Mission GP, Jones HS, O'Neill EC. The predictive value of postoperative intraocular pressures following trabeculectomy. Eye (Lond) 1994; 8 ( Pt 4):394-397

20. Asamoto A, Yablonski ME, Matsushita M. Predicting long-term results of trabeculectomy from early postoperative intraocular pressure levels. Ophthalmic Surg Lasers $1996 ; 27: 355-360$

21. Alwitry A, Moodie J, Rotchford A, Abedin A, Patel V, King AJ. Predictive value of early IOP in mitomycin-C augmented trabeculectomy. J Glaucoma 2007; 16:616-621

22. Karimi A, Lindfield D. Is a Day 1 postoperative review following ab interno Xen gel stent surgery for glaucoma needed? Clin Ophthalmol 2018; 12:2331-2335

23. Fea AM, Spinetta R, Cannizzo PML, Consolandi G, Lavia C, Aragno V, Germinetti F, Rolle T. Evaluation of Bleb Morphology and Reduction in IOP and Glaucoma Medication following Implantation of a Novel Gel Stent. J Ophthalmol 2017; 2017:9364910 
24. Lenzhofer M, Strohmaier C, Hohensinn M, Hitzl W, Sperl P, Gerner M, Steiner V, Moussa S, Krall E, Reitsamer HA. Longitudinal bleb morphology in anterior segment OCT after minimally invasive transscleral ab interno Glaucoma Gel Microstent implantation. Acta Ophthalmol 2019; 97:e231-e237

25. Midha N, Rao HL, Mermoud A, Mansouri K. Identifying the predictors of needling after XEN gel implant. Eye (Lond) 2019; 33:353-357

26. Buffault J, Baudouin C, Labbe A. $\operatorname{XEN}((\mathrm{R}))$ Gel Stent for management of chronic open angle glaucoma: A review of the literature. J Fr Ophtalmol 2019; 42:e37-e46

27. Arnljots TS, Economou MA. XEN Gel Stent exposure 7mo after primary implantation: a case report. Int J Ophthalmol 2019; 12:689-691

\section{OTHER CITED MATERIAL}

A. European Glaucoma Society. "Terminology and Guidelines for Glaucoma. 4th Edition, 2014." Retrieved 16 May 2019, from https://www.eugs.org/eng/guidelines.asp 


\section{FIGURE LEGENDS}

Figure 1. Mean intraocular pressure (IOP) and number of medications during the study.

Figure 2. Scatterplot of intraocular pressure (IOP) reduction as a function of post-operative IOP (last follow-up).

Figure 3. Mean intraocular pressure (IOP) and number of medications during the study, solo vs. combo group (The first row of numbers refers to the combo patients at each follow-up visit and the second row to the solo patients. The bars represent number of medications and the lines represent IOP).

Figure 4. Mean intraocular pressure (IOP) and number of medications in the standalone cross-linked collagen stent procedure (solo group) according to lens status (phakic or pseudophakic). (The first row of numbers refers to phakic patients at each follow-up visit and the second row to pseudophakic patients. The bars represent number of medications and the lines represent IOP). 


\section{TABLES}

Table 1. Baseline characteristics of the patient population with $\geq 9$ months of follow-up compared with the overall enrolled population.

\section{All Follow up $\geq 9$ months p-value}

\begin{tabular}{lccc} 
& \multicolumn{1}{c}{$(\mathbf{n = 2 9 8})$} & $(\mathbf{n = 1 7 1 )}$ & \\
\hline Age, mean \pm sd & $70.3 \pm 11.8$ & $70.5 \pm 11.8$ & 0.88 \\
Female, n (\%) & $149(50.0 \%)$ & $89(52.0 \%)$ & 0.70 \\
Left eye, n (\%) & $146(49.0 \%)$ & $87(50.9 \%)$ & 0.70 \\
Phakic, n $(\%)$ & $165(55.4 \%)$ & $98(57.3 \%)$ & 0.69
\end{tabular}

\section{Glaucoma type, $n(\%)$}

Primary open angle glaucoma

$235(78.9 \%)$

$134(78.4 \%)$

0.90

Exfoliative glaucoma

$39(13.1 \%)$

$27(15.8 \%)$

0.42

Juvenile glaucoma

$4(1.3 \%)$

$2(1.2 \%)$

0.93

Mixed mechanism glaucoma

$9(3.0 \%)$

$2(1.2 \%)$

0.22

Normal tension glaucoma

$7(2.3 \%)$

$3(1.8 \%)$

0.82

Uveitic glaucoma

$3(1.0 \%)$

$3(1.8 \%)$

0.79

Ocular hypertension

$1(0.3 \%)$

0.78 


\section{Previous laser treatment, n (\%)}

SLT

ALT
$58(19.5 \%)$

$1(0.3 \%)$
$47(27.5 \%)$

0.05

0.63
$1(0.6 \%)$

\section{Previous surgery, n (\%)}

Trabeculectomy

Deep sclerectomy

Iridectomy

Vitrectomy (epiretinal membrane)
$6(2.0 \%)$

$2(0.7 \%)$

$1(0.3 \%)$

$1(0.3 \%)$

$1(0.3 \%)$

$1(0.3 \%)$
Buckling

\author{
Keratoplasty
}

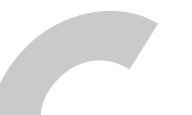

1

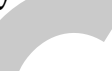


Pattern standard deviation, mean \pm sd

BCVA, mean \pm sd

Abbreviations: ALT, argon laser trabeculoplasty; BCVA, best-corrected visual acuity; IOP, intraocular pressure; SLT, selective laser trabeculoplasty. 
Table 2. Baseline characteristics of solo group (cross-linked collagen stent only) and combo group (cross-linked collagen stent implant combined with cataract surgery) treatment groups.

\begin{tabular}{|c|c|c|c|c|c|c|}
\hline & $\begin{array}{l}\text { Combo group } \\
\qquad(n=56)\end{array}$ & $\begin{array}{l}\text { Solo group } \\
(n=115)\end{array}$ & $\begin{array}{l}\text { p-value } \\
\text { (Solo vs. } \\
\text { Combo) }\end{array}$ & Phakic & $\begin{array}{l}\text { Pseudophakic } \\
(n=72)\end{array}$ & $\begin{array}{c}\text { p-value } \\
\text { (Phakic vs. } \\
\text { Pseudophakic) }\end{array}$ \\
\hline Age (years), mean \pm sd & $71.4 \pm 7.9$ & $70 \pm 13.3$ & & $62.2 \pm 15$ & $74.7 \pm 9.4$ & $<0.001$ \\
\hline Female, $\%$ & 31 & 58 & & 15 & 43 & 0.02 \\
\hline \multicolumn{7}{|l|}{ Glaucoma type, $n$} \\
\hline POAG & & 89 & 0.66 & 31 & 58 & 0.41 \\
\hline PXG & 8 & 19 & 0.71 & 8 & 11 & 0.84 \\
\hline Juvenile & & 2 & 0.33 & 2 & & 0.27 \\
\hline
\end{tabular}


Mixed mechanism glaucoma

NTG

Uveitic

Trabeculectomy

Deep sclerectomy

Iridectomy

Buckling

PKP

Previous surgery, $n$
1

0.81

1

0.79

0.55

1

0.72

2

0.55

0.72

3

0.55

3

0.45

0.71

1

0.79

0.79

0.71

1

0.71

0.71

0.79 
Acetazolamide, $\mathrm{n}$

Medications pre-op, mean \pm sd

IOP pre-op $(\mathrm{mmHg})$, mean $\pm \mathrm{sd}$

BCVA, mean $\pm \mathrm{sd}$
4

$$
2.5 \pm 1.0
$$

$$
3.25 \pm 1.0
$$

$<0.001$

$3.19 \pm 0.96$

$3.3 \pm 1$

$26.7 \pm 9.8$

$24 \pm 5.7$

0.06

$21.4 \pm 7.0$

$25.03 \pm 7.6$

0.003

0.80

$0.54 \pm 0.26$

$0.73 \pm 0.24$
$0.84 \pm 0.21 \quad 0.65 \pm 0.22$

$0.84 \pm 0.21 \quad 0.65 \pm 0.22$

0.001

Abbreviations: BCVA, best-corrected visual acuity; IOP, intraocular pressure; n, number; NTG, normal-tension glaucoma; OHT, ocular hypertension; PKP, Penetrating Keratoplasty; POAG, primary open-angle glaucoma; PXG, pseudoexfoliation glaucoma; sd, standard deviation. 
Table 3. Association between final intraocular pressure (IOP) and early post-operative IOP, and between final IOP and $\Delta$ in early post-operative IOP.

\section{Final IOP}

\section{$\leq 14 \mathrm{mmHg} \leq 16 \mathrm{mmHg} \leq 18 \mathrm{mmHg}$}

\begin{tabular}{|c|c|c|c|}
\hline Early post-operative IOP & & & \\
\hline 1 day IOP $<6 \mathrm{mmHg}$ & 0.91 & & \\
\hline 1 day $\mathrm{IOP}<8 \mathrm{mmHg}$ & 0.20 & & 0.29 \\
\hline 1 day IOP $<10 \mathrm{mmHg}$ & & 0.32 & 0.41 \\
\hline 1 week IOP $<6 \mathrm{mmHg}$ & 2 & 0.01 & 0.02 \\
\hline 1 week IC & 0.002 & 0.01 & 0.04 \\
\hline 1 week IOP $<10 \mathrm{~mm}$ & 0.02 & 0.003 & 0.03 \\
\hline 1 month IOP $<6 \mathrm{mmHg}$ & 0.70 & 0.78 & 0.61 \\
\hline 1 month IOP <8 mmHg & 0.002 & 0.12 & 0.28 \\
\hline 1 month IOP $<10 \mathrm{mmHg}$ & 0.02 & 0.01 & 0.01 \\
\hline
\end{tabular}

\section{$\Delta$ in early post-operative IOP}


$\Delta$ IOP day 1 - week $1<4 \mathrm{mmHg}$

$\Delta$ IOP day 1 - month $1<4 \mathrm{mmHg}$

$\Delta$ IOP week 1 - month $1<4 \mathrm{mmHg}$

$\Delta$ IOP day 1 - week $1<6 \mathrm{mmHg}$

$\Delta$ IOP day 1 - month $1<6 \mathrm{mmHg}$

$\Delta$ IOP week 1 - month $1<6 \mathrm{mmHg}$
0.32

0.79

4.41

0.04

0.07

0.13

$0.63 \quad 0.77$

0.13

0.08

0.09

0.15

0.09

0.14

0.25

0.03

0.02 
Table 4. Mean difference between baseline and the end of the follow-up period in intraocular pressure (IOP) and number of medications according to the treatment groups.

\section{IOP mmHg, Number of medications,}

\begin{tabular}{lll} 
& mean $\pm \mathbf{s d}$ & mean \pm sd \\
& $-7.4 \pm 7.9$ & $-2.32 \pm 1.31$ \\
\hline Overall & $-4.54 \pm 8.35$ & $-1.94 \pm 1.16$ \\
Combo & $-8.8 \pm 7.5^{*}$ & $-2.6 \pm 1.35^{* *}$ \\
Solo & $-10.88 \pm 9.79$ & $-2.7 \pm 1.42$ \\
Phakic & $-7.78 \pm 5.88$ & $-2.6 \pm 1.33$ \\
&
\end{tabular}

Abbreviations: sd, standard deviation

$* P=0.0032$ vs combo group

$* * P<0.0001$ vs combo group 
Table 5. Final results at the 12-month follow-up visit.

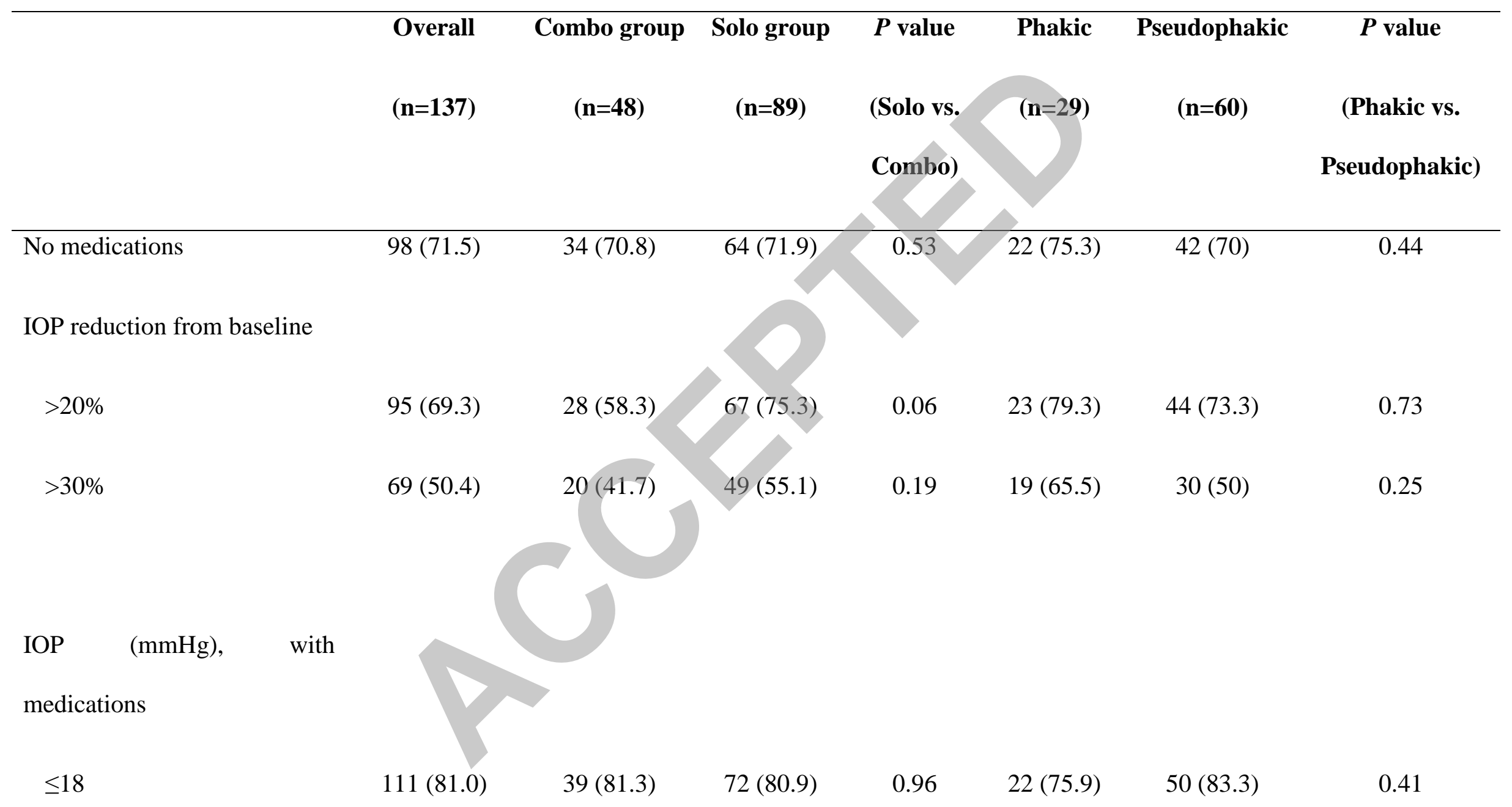

10 
$\leq 16$

$\leq 14$

OP $(\mathrm{mmHg}), \quad$ without

medications

$\leq 18$

$\leq 16$

$\leq 14$

$97(70.8)$

$34(70.8)$

$63(70.8)$

1

$21(72.4)$

$42(70.0)$

0.82

$59(43.1) \quad 17(35.4)$

$42(47.2)$

0.19

$18(62.1)$

$24(40.0)$

0.08

$\begin{array}{lllllll}84(61.3) & 28(58.3) & 56(62.9) & 0.60 & 17(58.6) & 39(65.0) & 0.73 \\ 74(54.0) & 23(47.9) & 51(57.3) & 0.29 & 17(58.6) & 34(56.7) & 0.96 \\ 48(35.0) & 11(22.9) & 37(41.6) & 0.03 & 15(51.7) & 22(36.7) & 0.18\end{array}$

Abbreviations: IOP, intraocular pressure; ns, not significant. Data is shown as number of patients (\%).

11 
Table 6. Post-operative complications.

\section{All Solo group Combo group}

\begin{tabular}{lccc}
\hline Hyphema & 33 & 15 & 18 \\
Hypoathalamia & 7 & 5 & 2 \\
Choroidal detachment & 16 & 12 & - \\
Fibrin reaction in the anterior chamber & 1 & 1 & - \\
Cross-linked collagen stent exposition & 1 & 1 & - \\
Perforation after needling & 1 & 1 & 1 \\
Stent rupture & 1 & 1 & - \\
Stent in the anterior chamber & 3 & 1 & 1 \\
Stent repositioning & & 1 & \\
\hline
\end{tabular}


Table 7. Needling procedures performed during the post-operative period.

\begin{tabular}{lccc}
\hline & Patients who & Overall & Needling \\
underwent & needling, $\mathbf{n}$ & procedures, \\
& needling, $(\boldsymbol{\%})$ & & mean \pm sd \\
\hline Combo $(\mathrm{n}=56)$ & $27(48.21)^{*}$ & 54 & $0.98 \pm 1.4$ \\
Solo (n=115) & $52(45.22)$ & 93 & $0.98 \pm 1.15$ \\
Phakic (n=43) & $19(44.19)^{* *}$ & 28 & $0.65 \pm 0.9$ \\
Pseudophakic $(\mathrm{n}=72)$ & $33(45.83)$ & 65 & $0.90 \pm 1.3$ \\
\hline
\end{tabular}

Abbreviations: $\mathrm{n}$, number, sd, standard deviation.

$* \mathrm{~K}^{2}=6.32, P<0.01$ vs. solo group

$* * \mathrm{~K}^{2}=9.45, P<0.002$ vs. pseudophakic group 
Table 8. Comparison of outcomes between studies.

\begin{tabular}{|c|c|c|c|c|c|c|c|}
\hline Author & Design & $\begin{array}{l}\text { Mean pre-op } \\
\text { IOP }(\mathrm{mmHg})^{*}\end{array}$ & $\begin{array}{l}\text { Mean post-op } \\
\text { IOP }(\mathrm{mmHg})^{*}\end{array}$ & \% IOP & $\begin{array}{l}\text { Mean pre-op } \\
\text { medication* }\end{array}$ & $\begin{array}{l}\text { Mean post-op } \\
\text { medication* }\end{array}$ & $\begin{array}{c}\text { \% medication } \\
\text { reduction }\end{array}$ \\
\hline Present study & Pro mc & $23.9(7.6)$ & $15.5(3.9)$ & 35.2 & $(14)$ & $0.5(1)$ & 83.3 \\
\hline $\begin{array}{l}\text { Galal et al. } \\
2017^{12}\end{array}$ & Pro sc & $16(4)$ & $12(3)$ & 23 & & $0.3(0.4)$ & 95 \\
\hline $\begin{array}{l}\text { Grover et al. } \\
2017^{7}\end{array}$ & Pro mc & $25.1(3.7)$ & $15.9(5.2)$ & & $3.5(1.0)$ & $1.7(1.5)$ & 38.5 \\
\hline $\begin{array}{l}\text { Fea et al. } \\
2017^{23}\end{array}$ & Pro sc & $21.8(2.8)$ & 14.9 & 31.6 & $2.92(1.16)$ & $0.5(0.53)$ & 83 \\
\hline $\begin{array}{l}\text { De Gregorio et } \\
\text { al. } 2018^{11}\end{array}$ & Pro sc & 22.53 . & $13.1(2.4)$ & 41.8 & $2.5(0.9)$ & $0.4(0.8)$ & 84 \\
\hline Mansouri et al. & Pro sc & $20(7.1)$ & $13.9(4.3)$ & 31 & $1.9(1.3)$ & $0.5(0.8)$ & 73.7 \\
\hline
\end{tabular}


$2018^{16}$

Heidinger et al. Retro sc

$2019^{8}$

Karimi et al. Retro me

$19.3(6.0)$

$2019^{15}$

Reitsamer et al. Pro mc

$2019^{18}$

Abbreviations: IOP, intraocular pressure; mc, multicenter; Pro, Prospective; Retro, Retrospective; sc, single center; sd, standard deviation. $21.4(3.6)$

$22.8(6.9)$

$17.1(5.9)$

22.7

$2.9(1)$

$1.8(1.4)$

37.9

69.2

$14.2(4.4)$

25.3

$2.6(1.1)$

$0.8(1)$

$0.9(1.1)$

66.7

*Data is presented as mean (sd). 


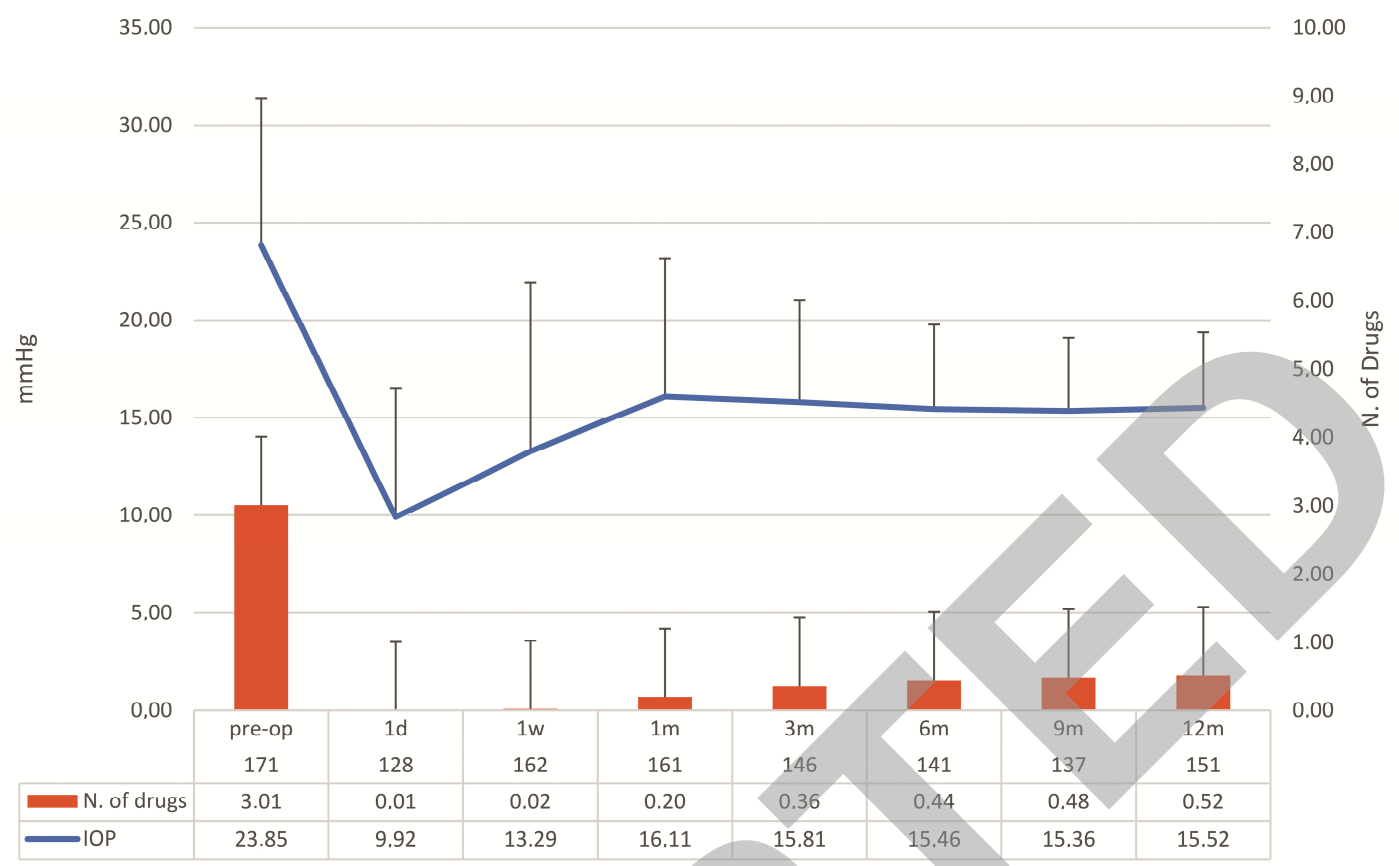

Copyright (C) 2020 Published by Wolters Kluwere on behalf बfASERS and ESCRS. Unauthorized reproduction of this article is prohibited. 


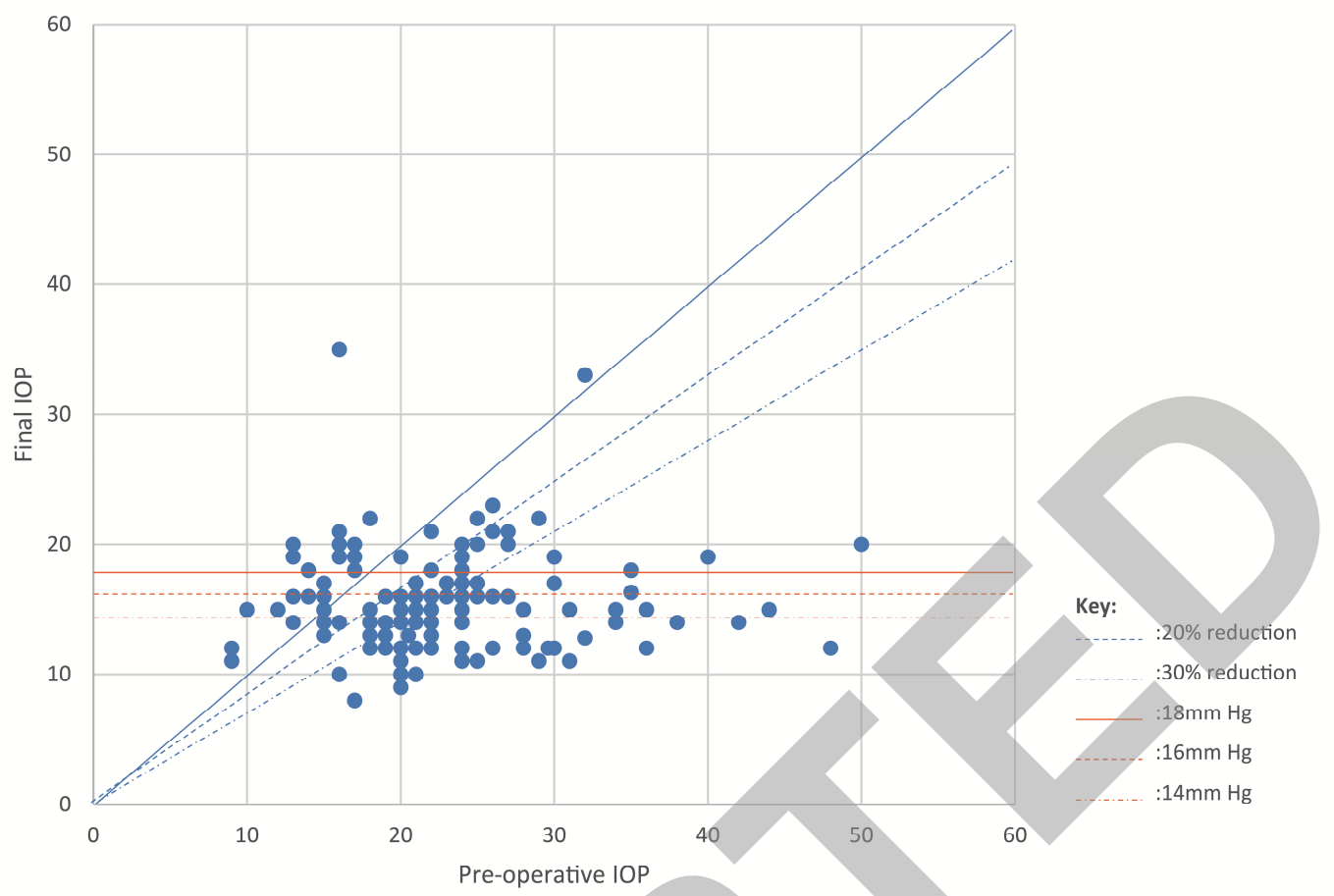

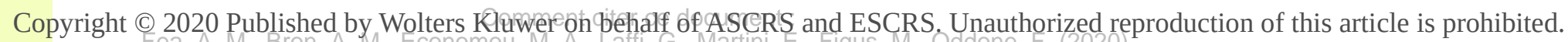
A real-life prospective study on the efficacy of the XEN 45 stent: a European study. Journal 


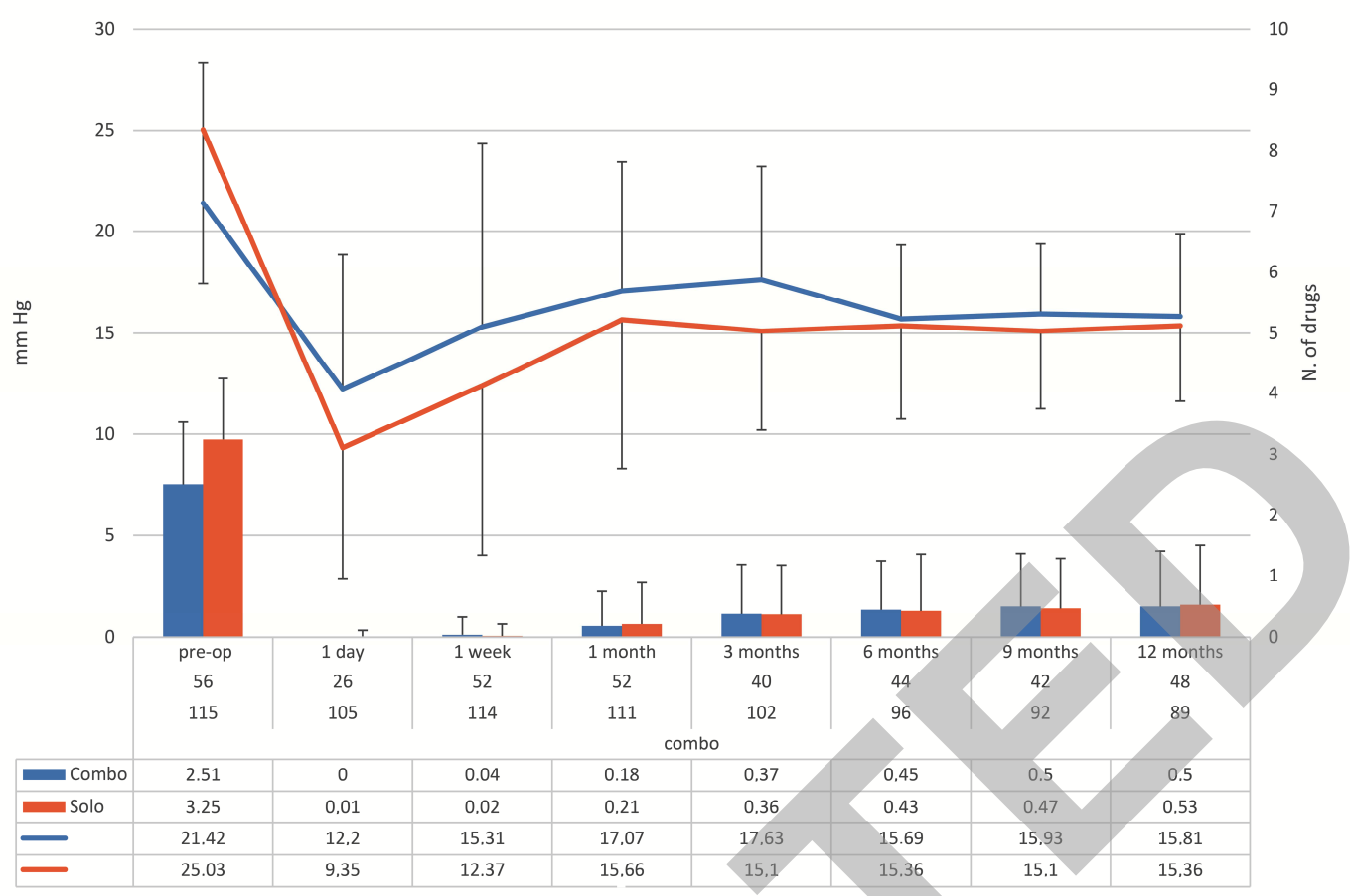

Copyright (C) 2020 Published by Wolters K1uwer on behaf Of ASCRS and ESCRS. Unauthorized reproduction of this article is prohibited. 


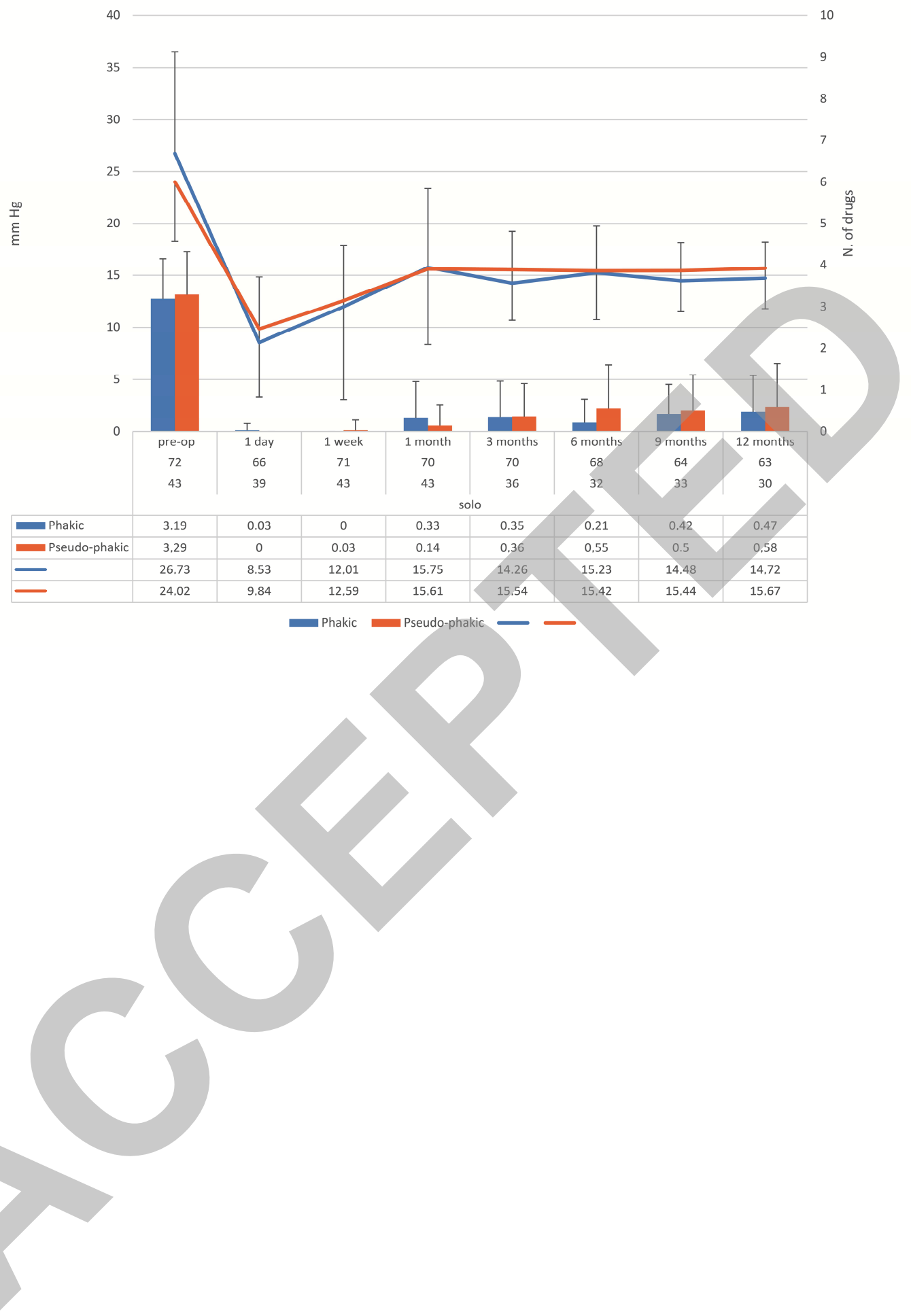

Copyright (C) 2020 Published by Wolters Kluwere A real-life prospective study on the efficacy of the XEN 45 stent: a European study. Journal of Cataract and Refractive Surgery, Epub ahead of print, 1-42., DOI : 10.1097/j.jcrs.0000000000000065 